\title{
Plasticity of Mesenchymal Stem Cells based on Immune Regulation Network
}

\author{
Tingting $\operatorname{Ren}^{1}$
}

\author{
${ }^{1}$ Department of Histology and Embryology, School of Medicine, Qingdao University, Qingdao 266000
}

\begin{abstract}
The immunomodulatory function of mesenchymal stem cells has received increasing attention and is widely used in the treatment of clinical immune diseases. The various signal-stimulating molecules during the inflammatory response are essential for the ability of MSCs to exert immunomodulatory effects and determine the fate of immune regulation in MSCs - pro-inflammatory and anti-inflammatory. Such plasticity relies on a regulatory network between immune cells and MSCs that is formed by cytokines, chemokines, and some small molecules. To gain a deeper understanding of the specific mechanisms by which MSCs exert immunomodulatory effects, it is necessary to clarify the factors involved in regulation, the series of cellular signaling pathways triggered by these factors, and the potential links between them. This article is based on these immune regulation networks, combined with the latest research trends, to provide a theoretical basis for better clinical improvement of MSCs treatment.
\end{abstract}

Keywords: Mesenchymal Stem Cells, Plasticity, Immune Cells, Cytokines, Immune Regulation Network

Mesenchymal stem cells (MSCs), a pluripotent stem cell, were first discovered in the bone marrow stroma in the 1860 s and were later defined as "colony-forming unit fibroblast" ${ }^{[1]}$. At present, it is found that MSCs exist in various tissues, such as fat, bone marrow, umbilical cord, periosteum, etc., and can differentiate into adipocytes, osteoblasts and chondrocytes ${ }^{[2]}$, and can also be transdifferentiated into tissues of ectoderm and endoderm. Cells ${ }^{[3]}$, but the specific biological mechanisms of this phenomenon remain to be elucidated. Due to the expression of various markers on the surface of MSCs, such as CD29, CD51, CD73, CD90, CD105, nestin, leptin receptor, Gli1 (glioma-associated oncogene homolog 1) and FAP (Fibroblastactivation protein), there is currently no recognized specificity. Mark. International Cell Therapy Association affirmed MSCs defined as CD73, CD90 and CD105 (positive rate >95\%), low expression (positive rate $<5 \%$ ) CD45, CD34, CD11 or CD14, CD79a or CD19, HLA-DR ${ }^{[4]}$, recently studied CD271 (low affinity nerve growth factor receptor, LNG-FR) is one of the markers for the isolation of high purity MSCs ${ }^{[5]}$. These markers determine the function of MSCs in the inflammatory response - immune regulation and tissue regeneration. During the inflammatory reaction, immune cells release various inflammatory cytokines (IFN- $\gamma$, TNF, IL-1, IL-17, etc.), which constitute a local inflammatory microenvironment. MSCs that enter the human body by intravenous injection recognize inflammatory factors through their surface markers. , thus being recruited to the site of inflammation. After receiving inflammatory factor stimulation signals, MSCs are activated and secrete various cytokines, including TGF- $\beta 1$, HGF, NO, IL-10, IGF, EGF, IDO, PD-L1, TSG-6, etc.Inhibits inflammation and strengthens tissue repair in two ways - cell replacement and cell empowerment. Previous studies have attempted to use the differentiation potential of MSCs to replace damaged cells, such as cardiomyocytes, endothelial cells, and hepatocytes, thereby promoting the repair and regeneration of related organs ${ }^{[6-9]}$. However, in clinical research and preclinical studies, there is increasing evidence that MSCs are poorly transplanted and have a short graft life ${ }^{[10-11]}$, suggesting that the main way in which MSCs play a role in tissue repair and regeneration is not cell replacement. It is cell empowerment. Through interaction with inflammatory factors, MSCs inhibit inflammation and selectively secrete growth factors, on the one hand, promote the proliferative ability of local precursor cells in damaged tissues, and on the other hand, recruit peripheral precursor cells to participate in local tissue repair ${ }^{[12]}$. It can be seen that the immunomodulatory capacity of MSCs is not constitutive but inducible. However, with the intensity and type of inflammatory response, the immunomodulatory capacity of MSCs presents two diametrically opposite results, promoting inflammation and inhibiting inflammation. It has been reported that in the acute phase of inflammatory response, MSCs can be successfully treated in patients with graft-versus-host disease (GvHD), but MSCs are treated before the inflammatory response, but it has no effect and even worsens the condition ${ }^{[13-14]}$.

\section{MSCs and immune regulation}

Since the initial discovery of bone marrow mesenchymal stem cells inhibiting $\mathrm{T}$ cell proliferation in experiments ${ }^{[15,16]}$, more and more scientists have been studying their immunomodulatory properties.

This article is published under the terms of the Creative Commons Attribution License 4.0 Author(s) retain the copyright of this article. Publication rights with Alkhaer Publications. Published at: http://www.ijsciences.com/pub/issue/2019-05/

DOI: 10.18483/ijSci.2096; Online ISSN: 2305-3925; Print ISSN: 2410-4477 
Many studies have shown that the immunomodulatory capacity of MSCs is mainly dependent on the regulation of immune cells, including dendritic (DC) cells, B cells, T cells, natural killer (NK) cells and macrophages. The regulation of immune cells by MSCs is mainly dependent on several key steps ${ }^{[17-20]}$. MSCs are able to inhibit the maturation of DC cells, resulting in a tolerant phenotype that subsequently leads to increased production of Tregs. For B cells and T cells, MSCs mainly inhibit their proliferation and differentiation. Studies have shown that the inhibitory function of MSCs mainly plays a role in the proliferation of $\mathrm{T}$ cells, specifically the G1 phase or G0/G1 transition, inhibiting the differentiation into TH1 and TH17 subpopulations, and promoting the formation of Tregs. At the same time, MSCs can down-regulate the killing ability of NK cells and promote the secretion of TGF- $\beta$ by macrophages, further promoting the production of Tregs. Subsequently, the immune regulation response can continue to be mediated by Tregs. In the clinical treatment of sepsis, the conversion of macrophages from pro-inflammatory to anti-inflammatory is also the basis for the efficacy of MSCs ${ }^{[21,22]}$. It can be seen that various signal-stimulated molecules during the inflammatory response are essential for the ability of MSCs to exert immunomodulatory effects and determine the fate of immune regulation of MSCs. A series of studies on the communication between inflammatory responses and MSCs-mediated immunosuppressive factors revealed that immunomodulation of MSCs is highly flexible ${ }^{[12]}$. Such plasticity depends on the regulatory network formed between cytokines, chemokines and some small molecules between immune cells and MSCs. The general process is the secretion of signaling molecules by immune cells, such as IFN- $\gamma$ and TNF- $\alpha$, and then acting on MSCs. It stimulates the secretion of immunomodulatory molecules (NO, IDO, etc.), which in turn acts on immune cells to regulate their immune activity ${ }^{[23]}$. Studies have also found that cytokines secreted by MSCs act on themselves and regulate their own secretion capacity, such as TGF- $\beta^{[24]}$. To gain a deeper understanding of the specific mechanisms by which MSCs exert immunomodulatory effects, it is necessary to clarify the factors involved in regulation, the series of cellular signaling pathways triggered by these factors, and the potential links between them. In this way, the therapeutic effect of MSCs can be better improved clinically. The immunoregulators that have been found so far include IFN- $\gamma$ (Interferon- $\gamma$ ), TGF- $\beta$ (Transforming Growth Factor- $\beta$ ), NO (Nitric Oxide), IDO (Indoleamine 2, 3-dioxygenase), and PD-L1 (Programmed Death). -1 Ligands), IL-10 (Interleukin-10), HLA-G (Human Leucocyte Antigen-G), LIF (Leukemia Inhibitory Factor), PGE2 (Prostaglandin E2), HGF (Hepatocyte Growth Factor).

The involvement of IFN- $\gamma$ in MSCs in vivo, tissue damage, inflammation or invasion of exogenous substances can lead to the activation of T cells, which in turn secrete IFN- $\gamma$, TNF- $\alpha$, IL- $1 \alpha$ and IL- $1 \beta$. A pro-inflammatory cytokine that further induces the production of chemokines by cells ${ }^{[25]}$. These chemokines bind to cells expressing CXCR3, including $\mathrm{T}$ cells, and are involved in the immune regulation of MSCs ${ }^{[26]}$. IFN- $\gamma$ plays an extremely important role in this process, determining the immune response of $\mathrm{T}$ cells. Studies have shown that low concentrations of IFN- $\gamma$ induce MSCs to express MHC class II molecules, which act as antigen-presenting cells to promote proinflammatory effects ${ }^{[27]}$; while high concentrations of IFN- $\gamma$ induce MSCs to express anti-inflammatory cytokines to perform anti-inflammatory effects $[28,29]$. When IFN- $\gamma$ is applied to MSCs, it also induces expression of iNOS ${ }^{[30]}$ and IDO ${ }^{[31]}$ and affects the activation of intracellular signaling pathways, such as nuclear factor kappa B and Runt-related transcription factor 2 pathways ${ }^{[32,33]}$. Thereby inhibiting the inflammatory response. In addition, recent studies have found that IFN- $\gamma$-induced MSCs express the ligands B7H1 (PDL1) and B7DC (PDL2) of the $\mathrm{T}$ cell inhibitory receptor PD1, and exert immunosuppressive effects by directly inhibiting $\mathrm{T}$ cell function ${ }^{[34]}$. IFN- $\gamma$ binds to IFN- $\gamma \mathrm{R}$ on the surface of MSCs, phosphorylating and nuclear translocation of STAT1, thereby driving target gene expression of immunoregulatory factors, including PGE2, IDO and TNF- $\alpha{ }^{[35]}$. Another study found that IFN- $\gamma$ also shadows STAT3, phosphatidylinositol-3-kinase, AKT, and mitogen-activated protein kinase (ERK) expression, as well as mTOR signaling ${ }^{[36,37]}$. It has been demonstrated that IFN- $\gamma$ promotes the immunomodulatory function of MSCs by temporarily activating STAT1 and STAT3 and decreasing mTOR activity. In mouse experiments, IFN- $\gamma$ inhibits mTOR signaling through an ERK1/2-dependent mechanism and promotes pSTAT1 nuclear translocation and enhances the expression of immunoregulatory factors. Furthermore, in cell experiments, after mTOR was inhibited, MSCs significantly enhanced the T cell-mediated immune response, down-regulated the expression of IFN- $\gamma$, TNF- $\alpha$ and IL-17, but promoted IL-4. Expression ${ }^{35]}$. mTOR is a serine/threonine kinase that can be activated by AKT and can respond to many extracellular stimuli to control cell proliferation and metabolism ${ }^{[38,39]}$. In a comprehensive study, when MSCs received short-term stimulation with IFN- $\gamma$, phosphorylation of STAT1 and STAT3 was significantly enhanced, resulting in dephosphorylation of mTOR and its downstream target S6. And studies have shown that STAT1 controls the expression of molecules involved in immune regulation, such as $\mathrm{Cd} 274^{[40]}$, Nos2 ${ }^{[41]}$ and Il18bp. However, long-term stimulation with IFN- $\gamma$ induces dephosphorylation of STAT1 and STAT3, and enhances phosphorylation of mTOR and S6. Experiments have shown that when STAT3 phosphorylation is inhibited, it reduces the ability of MSCs to inhibit T cell proliferation. Since high concentrations of IFN- $\gamma$ also potentiate the phosphorylation of STAT1 and STAT3 and the dephosphorylation of mTOR, it is clinically possible to stimulate MSCs with high concentrations of IFN- $\gamma$ to synergistically enhance immunosuppressive effects. This effect localizes to genes that up-regulate genes involved in immune regulation and down-regulate 
genes involved in cell proliferation and differentiation [35]

\section{IFN- $\gamma$-induced immune regulation}

IFN- $\gamma$ induces $\mathrm{MSCs}$ to secrete immunoregulatory factors such as IDO, PD-L1, HLA-G, PGE2, HGF, TSG-6, IL-10, and regulate immune response.

\section{IDO}

IDO is a rate-limiting enzyme that degrades tryptophan to kynurenine, and its expression increases in inflammatory or hypoxic conditions. Recent studies have shown that MSCs can exert immunosuppressive effects by secreting functional IDO ${ }^{[42]}$. Especially for humans, IDO is one of the main ways in which MSCs function.

In 2004, the Meisel team demonstrated for the first time that MSCs can express IDO in an IFN- $\gamma$-dependent manner, that is, inflammation-induced IFN- $\gamma$ secretion, which induces the production of IDO by MSCs, and believes that the resulting tryptophan depletion in T cells is its function. The key mechanism of inhibition effect ${ }^{[43]}$. According to its view, tryptophan depletion has two consequences, one is the accumulation of metabolites, and the other is complete decomposition. In order to determine its exact mechanism, 1-methyl-L-tryptophan was used to inhibit IDO activity, and it was found that $\mathrm{T}$ cell proliferation was restored in vitro, indicating that IDO is introduced by accumulation of the tryptophan metabolite kynurenine. Inhibition of $\mathrm{T}$ cells by MSCs ${ }^{[44]}$. Regarding the specific molecular mechanism by which IDO works, recent studies have shown that IDO can induce $\mathrm{T}$ cell immunosuppression through the Vav1/Rac signaling pathway (GEF pathway). Activated Vav1 regulates $\mathrm{T}$ cell development and activation by activating calcium channels, ERK-MAPK, NF- $\kappa \mathrm{B}$, and by NFAT pathway, and inhibits $\mathrm{T}$ cell proliferation when its expression is decreased or inactivated. Further studies have shown that IDO inhibits Vav1 mRNA expression, Vav1 phosphorylation, and activation of its downstream targets, while Rac activity is dependent on Vav1, resulting in inhibition of Vav1/Rac signaling pathway, thereby inhibiting $\mathrm{T}$ cell proliferation ${ }^{[45]}$.

\section{PD-L1}

PD-1 is a signaling protein that is mainly expressed on the surface of activated $T$ cells and $B$ cells ${ }^{[46]}$, when with ligands, binding of PD-L1/B7-H1 or PD-L2/B7-DC initiates an inhibitory signal for cell activation or proliferation ${ }^{[47-49]}$, thereby suppressing the immune response. The overall role of the PD-1 pathway in $\mathrm{T}$ cell homeostasis is evident, and studies have shown that PD-1 knockout mice exhibit splenomegaly and increased susceptibility to autoimmune diseases [50, 51]. With the deeper understanding of the PD-1 pathway, its important role in the mouse model of GvHD ${ }^{[52]}$ and type I diabetes ${ }^{[53]}$ was also found. Although the affinity of PD-L2/PD- 1 is 2-6 times higher than that of PD-L1/PD-1, PD-L1/PD is used in vivo because the expression level of PD-L2 is much lower than that of PD-L1. -1 is predominant ${ }^{[54]}$.
IFN- $\gamma$ induces MSCs to express membrane-bound and soluble PD-L1, and membrane-bound PD-L1 inhibits T cell proliferation and function via contact-dependent interaction with PD-1 on the surface of T cells ${ }^{[55,56]}$, soluble PD -L1 further inhibits the secretion of IL-2 by activated $\mathrm{T}$ cells. In molecular mechanism, MSCs secrete soluble PD-L1 to bind to PD-1 on the surface of $\mathrm{T}$ cells, inhibit the phosphorylation of AKT, leading to up-regulation of downstream $\mathrm{FOXO} 3$ expression, and up-regulation when PD-L1/PD-1 is blocked. FOXO3 reversed down-regulation, but only partially restored AKT phosphorylation, demonstrating that MSCs can affect AKT phosphorylation through a variety of immunoregulatory factors (such as IDO). The AKT pathway regulates a variety of cellular processes such as proliferation, apoptosis, and cytokine production ${ }^{[57]}$. FOXO3 has been shown to be the core of the inflammatory process, and its deletion causes a disorder in the activation and proliferation of $\mathrm{T}$ cells [58].

\section{HLA-G}

HLA-G is an atypical molecule of the HLA family, and the initial transcript is selectively cleaved to produce four membrane-bound molecules (HLA-G1-HLA-G4) and three soluble molecules (HLA-G5-HLA-G7). It plays an important role in immune regulation ${ }^{[59]}$. HLA-G is generally thought to mediate immune tolerance between the fetus and the mother, but there are differences as to whether it mediates the immunosuppressive effects of MSCs. Studies have reported that HLA-G is mainly present in the intracellular ${ }^{[60]}$, but studies have also reported that MSCs do not express intracellular HLA-G ${ }^{[61]}$. Recent studies on epigenetics have shown that inhibition of DNA methylation enhances MSCs expression of HLA-G1 and HLA-G3 ${ }^{[62]}$. It can be speculated that the expression of HLA-G in MSCs is inducible rather than constitutive, and MSCs mainly express intracellular HLA-G, but not membrane-bound HLA-G.

A variety of cytokines (including IDO, IL-10) can affect the expression of HLA-G, and there is also a relationship between them. IDO can induce the expression of HLA-G on the cell membrane surface ${ }^{[63]}$. IL-10 can up-regulate the expression of membrane-bound HLA-G and its receptors ${ }^{[64]}$. In turn, HLA-G can also regulate the cytokine balance by increasing IL-10 secretion, inducing Th1/Th2 balance toward Th2 tilt. ${ }^{[65]}$. Regarding the HLA-G-mediated immune regulation mechanism, studies have found that HLA-G is involved in the activation of phosphatase SHP-2, which inhibits the mTOR pathway in T cells and prevents activated $T$ cells from entering G0/G1. The transformation phase, in turn, inhibits $\mathrm{T}$ cell proliferation ${ }^{[66]}$. Recently, there have been reports that HLA-G can affect the production of Tregs through the PD1/PD1L pathway ${ }^{[67]}$.

\section{PGE2}

The precursor of PGE2 is arachidonic acid, constitutive cyclooxygenase (COX1) or inducible cyclooxygenase(COX2), PG synthase metabolism, can 
be induced by pro-inflammatory cytokines (IL-1 $\beta$, IFN- $\gamma$, and TNF- $\alpha)^{[68]}$ and participate in the regulation of immune responses at different stages. Studies have shown that MSCs form PGE2, and PG can also regulate the proliferation of MSCs by differentially activating cAMP-dependent protein kinases ${ }^{[69]}$. During co-culture with immune cells, MSCs produced a significant increase in PGE2, suggesting that up-regulation of PGE2 expression may be dependent on immune cell stimulation ${ }^{[70]}$. Further studies have found that when MSCs are stimulated by T cells, they up-regulate the expression of COX1/COX2, thereby producing more PGE2 ${ }^{[71]}$, and attenuating the immune response by inhibiting the activation and proliferation of $\gamma \delta \mathrm{T}$ cells and NK cells ${ }^{[72]}$. In addition, PGE2 can up-regulate IL-10 expression by regulating JAK-STAT signaling pathway, and synergistically regulate immune response ${ }^{[73]}$. In addition to inhibiting $\mathrm{T}$ cells, recent studies have also found that PGE2 produced by the COX2 pathway in MSCs can induce macrophage to switch from proinflammatory phenotype (M1) to anti-inflammatory phenotype (M2) by altering metabolic status. Inhibition of its immune function ${ }^{[749}$. However, although a large number of experiments have shown that PGE2 inhibits the immune response, some studies have reported its pro-inflammatory effects. PGE2 produced by MSCs can suppress Th1 response and enhance immune response by promoting Th17 response $^{[75]}$.

\section{HGF}

HGF is a hepatocyte mitogen. In a murine model of allogeneic bone marrow transplantation, rhHGF can be used to improve acute GVHD ${ }^{[76]}$. Early studies have shown that HGF secreted by MSCs binds to the specific transmembrane receptor c-Met, which drives the signal transduction pathway mediated by MAPK and PI3K, phosphorylates STAT3 ${ }^{[77]}$, inhibits T cell proliferation ${ }^{[78]}$, and Induction of Tregs amplification [79]. HGF can also inhibit $\mathrm{T}$ cell responses in a synergistic manner with TGF- $\beta$, and it has been found that blocking the expression of both completely restores lymphocyte proliferation ${ }^{[78]}$. In addition, HGF can also induce monocyte-derived (M0)-DCs to exhibit immune tolerance and reduce pro-inflammatory function by inducing secretion of other cytokines (IDO and IL-10) ${ }^{[80]}$. Further studies have shown that HGF up-regulates IL-10 expression in monocytes via ERK1/2 signaling ${ }^{[81]}$. In recent years, studies have also found that $\mathrm{HGF}$ can enhance $\mathrm{HO}-1$ transcription and post-transcriptional pathways through c-Met signaling, thereby promoting HO-1 production ${ }^{[82]}$. In a mouse model of endotoxemia, it has been found that HO-1 can regulate IL-6 / IL-10 balance and exert an anti-inflammatory effect ${ }^{[83]}$. From this point of view, the HGF / HO-1 / IL-10 pathways are interrelated and may play a more important role in the immune regulation of MSCs.

\section{TSG-6}

TNF- $\alpha$-activated gene/protein-6 (TSG-6) is an inflammation-associated secreted protein belonging to the family of hyaluronic acid-binding proteins. During inflammation and tumorigenesis, TSG-6 can participate in cell-to-cell interactions between cells and matrices through interactions with matrix-related molecules ${ }^{[84]}$. Studies have shown that the expression of TSG-6 in MSCs is inducible and can be used by many pro-inflammatory mediators (IFN- $\gamma$, TNF- $\alpha$,IL-1 $\beta$, LPS) is induced and rapidly secreted to participate in anti-inflammatory responses [85]. TSG-6 exerts an anti-inflammatory effect by regulating the inflammatory network of proteases and inhibiting the migration of neutrophils to the site of inflammation ${ }^{[85]}$. In an autoimmune disease model, TSG-6 also potentiates immune tolerance by inhibiting the maturation of Th1 ${ }^{[86]}$. Recent studies have found that TSG-6 secreted by MSCs inhibits the immune response affected by BMP-2 (bone morphogenetic protein 2) via the p38 and MEK mitogen-activated protein kinase pathways. At the same time, high dose of BMP-2 can induce the expression of inflammatory factors in THP-1 cells and the expression of anti-inflammatory factor TSG-6 in MSCs. Inflammatory cytokines are released from THP-1 cells, forming a local inflammatory response, whereas TSG-6 secreted by MSCs interferes with the inflammatory response of THP-1 cells via p38 and ERK in the MAPK pathway ${ }^{[87]}$. In addition, studies have found that TSG-6 can attenuate excessive inflammation caused by severe burns by inhibiting P38 and JNK signaling pathways ${ }^{[88]}$. TSG-6 also inhibits chemokine function by inhibiting chemokine/glycosaminoglycan interactions, thereby inhibiting neutrophil migration ${ }^{[89]}$.

\section{IL-10}

IL-10 is a pleiotropic immunomodulatory factor that affects both innate immunity and immune immunity [90].

Earlier studies have demonstrated that IL-10 can directly regulate $\mathrm{T}$ cells by modulating the balance of Th1/Th 2 cytokines ${ }^{[91]}$, and can also regulate $T$ cells by regulating the presentation of antigen-presenting cells and inducing Tregs ${ }^{[92,93]}$. Molecular studies have also found that there is a feedback loop between IL-10 and miRNA, IL-10 can regulate the production of certain specific miRNAs, which in turn can regulate their production before IL-10 transcription, thereby controlling anti-inflammatory in vivo. The balance of response and proinflammatory response ${ }^{[94]}$. Regarding the mechanism of action of IL-10, recent studies have shown that IL-10 expression is tightly controlled by IFN- $\gamma$ and itself, and it can both inhibit its own expression and promote expression through positive feedback ${ }^{[95]}$. IL-10 signals through STAT3, the pathway exerts an anti-inflammatory effect, and IL-10 receptor (IL-10R) is expressed on the surface of macrophages, NK cells, T cells, DC cells, B cells, and mast cells, and when they are combined, JAK1 is activated, and Phosphorylation of the downstream target STAT3 is activated, then enters the nucleus, activates specific target genes, and inhibits the expression of pro-inflammatory genes at the transcriptional level ${ }^{[96]}$. However, there are many claims about the cellular source of IL-10. Although 
most people believe that $\mathrm{T}$ cells are the main source of IL-10, while MSCs produce almost no IL-10, and MSCs stimulate their secretion only by contact, some studies have found that MSC2 induced by TLR3 produces high levels. IL-10 ${ }^{[97]}$. For the reason that MSCs produce almost no IL-10, it has been found that fatty MSCs form PDCD4 and PDCD4 is inhibited the production of IL-10, based on this, suggests that the expression of PDCD4 may cause MSCs to not produce IL-10 ${ }^{[98,99]}$. For the pathway of IL-10 production by MSCs, studies have also shown that IL-10 produced by T cells stimulates $\operatorname{Tr} 1$ to produce IFN- $\beta$ and acts on MSCs, which induces an increase in the transcription level of TLR3, resulting in IL-10 production by $\mathrm{MSCs}^{[100]}$. In summary, to date, whether IL-10 is derived from MSCs and mediates its immunosuppressive effect remains to be confirmed.

\section{iNOS}

In vivo, NO is a gaseous bioactive molecule produced by nitric oxide synthase (NOS) and involved in homeostasis and immune regulation. In mice, it has been found that NO inhibits the immune response. In the absence of NO, MSCs recruit $\mathrm{T}$ cells to exert pro-inflammatory effects, and when iNOS is inhibited, it also attenuates the immunosuppressive effects of MSCs ${ }^{[101]}$. NOS is also grouped into constitutive and induced, and has a tissue-specific expression pattern ${ }^{[102]}$. In the current study, only amnion-derived MSCs in all MSC types can mediate immunosuppression by secreting NO ${ }^{[103]}$. NO produced by $\mathrm{T}$ cells mediates lower levels of $\mathrm{T}$ cell proliferation through STAT-5 phosphorylation. By inducing NOS to activate NO produced by iNOS, it can inhibit the phosphorylation of STAT-5 and arrest the cell cycle. The specific mechanism that causes these two opposite results is still unclear, and from the dose-dependent effects of NO that have been confirmed, it is possible that the amount of NO produced by the two is different, and T cells produce less NO, while MSCs More NO is generated to activate the negative feedback mechanism [101]. Further studies have also found that NO produced by activated MSCs can affect MAPK and nuclear factor $\kappa \mathrm{B}$ in addition to affecting JAK-STAT pathway, further reducing the expression of pro-inflammatory cytokines at the gene level ${ }^{[104]}$.

\section{TGF- $\beta$}

TGF- $\beta$ is a widely recognized anti-inflammatory cytokine that is present in a variety of inflammatory processes.

The immunosuppressive effects that MSCs mediate by TGF- $\beta$ have been confirmed in a mouse model of ragweed-induced asthma. Intravenous MSCs inhibit Th2-induced allergic reactions and reconstitute physiological balance through TGF- $\beta^{[105]}$. However, recent experiments have found that TGF- $\beta$ alone inhibits proliferation of $\mathrm{T}$ cells, but addition to co-cultures of spleen cells and MSCs eliminates the immunosuppressive effects of MSCs and even promotes immune responses ${ }^{[106]}$. Such a discovery has greatly expanded people's understanding of TGF- $\beta$.
Further animal studies indicate that TGF- $\beta$ only acts on MSCs without affecting other immune cells and inhibits iNOS transcription in a Smad3-dependent manner, specifically inhibiting the activity of the iNOS promoter induced by inflammatory cytokines, There is no effect on the degradation of its mRNA or iNOS protein. Because of the species differences in the immunosuppressive mechanisms of MSCs, iNOS is required in mice, and IDO is required in humans, so human MSCs experiments were subsequently performed and the same inhibitory effects were also found. It was also found that TGF- $\beta$ has a dose-dependent effect on MSCs, and high doses of TGF- $\beta$ significantly reduce the expression of TGF- $\beta$ II bound to the extracellular membrane, thereby attenuating its effect on MSCs ${ }^{[106]}$. In addition to the action of TGF- $\beta$, which is not secreted by itself, MSCs are also affected by TGF- $\beta$ secreted by themselves. Experiments have found that activated MSCs also secrete TGF- $\beta$, which in turn acts on itself and inhibits its own immunosuppressive effects ${ }^{[106]}$.

\section{LIF}

LIF is a glycoprotein cytokine that can expressed inducibly in almost all tissues and participates in many process of the body, especially humoral immunity and cellular immunity ${ }^{[107,108]}$. During the inflammatory response, the level of LIF is upregulated ${ }^{[109]}$. Although research on the involvement of LIF in immune regulation has been underway for a long time, little is known about whether it mediates the immunosuppressive effects of MSCs. Until 2009, Nasef et al. reported that the immunosuppressive effects of MSCs were associated with increased expression of LIF ${ }^{[110]}$. The secretion of LIF was significantly increased during MSCs co-culture with T lymphocytes. Studies have further shown that pro-inflammatory cytokines secreted by $\mathrm{T}$ cells cause an increase in the secretion of LIF, indicating the role of LIF in the immunosuppression of MSCs ${ }^{[111]}$.

LIF can mediate immunosuppressive effects by directly inhibiting $\mathrm{T}$ cell activity or indirectly inducing Tregs production ${ }^{[112]}$. And LIF can also regulate the production of HLA-G, and there is a positive correlation with it. When the production of LIF is suppressed, the expression of HLA-G is also reduced ${ }^{[113]}$. There are few studies on the specific molecular mechanism of LIF involved in immune regulation. Currently, only the LIF-trophoblast-IL-10 pathway can regulate the activation of monocytes/macrophages by IFN- $\gamma$, and this pathway is STAT1 inhibition, STAT3 activation $^{[114]}$.

\section{Discuss}

In the immune system, immune cells and non-immune cells in a complex network of cytokines, which are tightly linked each other,and the cytokine network is also a potential target for immunotherapy ${ }^{[115]}$. These cytokines constitute a platform for cell communication and interaction and induce biological consequences of inflammatory responses. A large number of studies have shown that each cytokine can act on immune 
regulation alone. This may be due to the presence of many corresponding receptors on the surface of MSCs. After receiving these stimuli, the signal pathways initiated a cross talk each other .Blocking/neutralization experiments have also shown that the immunosuppressive function of MSCs cannot be completely shut down. From the current research, the premise of MSCs to play an immunoregulatory role is that activation of the pro-inflammatory cytokine IFN- $\gamma$ must be initiated before the expression of various immunoregulatory factors is initiated. As can be seen from the above, these immunoregulators do not function independently, but are related to each other. This association is not only reflected in IFN- $\gamma$, but also in signaling pathways, modes of action, and ultimately effects. For example, HLA-G, PGE2, HGF, IL-10, and iNOS all involve the JAK/STAT signaling pathway. HGF can synergistically inhibit T cell responses with TGF- $\beta$ and also promote the expression of IDO and IL-10. In addition, PGE2 also promotes IL-10 expression. TGF- $\beta$ attenuates the production of NO by MSCs by inhibiting the promoter activity of iNOS. Finally, the immune response is inhibited in three ways: 1 . inhibiting the proliferation of immune cells; 2 . inhibiting the function of immune cells; 3. promoting the production of Tregs. Although the adjustment path is different, the final effect is the same, reflecting the principle of "efficient and precise" biological response. Although MSCs mainly exert immunosuppressive effects, they are initially induced by pro-inflammatory cytokines, and depending on the amount and duration of stimulation, in addition to exerting anti-inflammatory effects, it also promotes inflammatory reactions to some extent.

And some anti-inflammatory cytokines also exhibit immune-promoting effects, such as NO, at low levels. Therefore, to accurately control the immunomodulatory properties of MSCs, this balance must be controlled. In summary, this review describes the specific causes of MSCs' immunomodulatory effects from the perspective of the immune regulation network of MSCs and related signaling pathways. Understanding and interpreting this regulatory network can provide more detailed information on MSCs-based immunotherapeutic strategies.

\section{References}

1. Friedenstein AJ, Chailakhjan RK, Lalykina KS. The development of fibroblast colonies in monolayer cultures of guineapig bone marrow and spleen cells. Cell Tissue Kinet.1970;3(4):393-403.

2. Pittenger MF, Mackay AM, Beck SC, Jaiswal RK, Douglas R, Mosca JD, Moorman MA, Simonetti DW, Craig S, Marshak DR. Multilineagepotential of adult human mesenchymal stem cells. Science.1999;284(5411):143-147.

3. Jiang Y, Jahagirdar BN, Reinhardt RL, Schwartz RE, Keene CD, Ortiz-Gonzalez XR,Reyes M, Lenvik T, Lund T, Blackstad M, Du J, Aldrich S, Lisberg A, Low WC, Largaespada DA, Verfaillie CM. Pluripotency of mesenchymal stem cells derived from adult marrow.Nature. 2002; 418(6893): 41-49.

4. Dominici M, LeBlanc K, Mueller I, Slaper-Cortenbach I, Marini F, Krause D,Deans R, Keating A, Prockop Dj, Horwitz E. Minimal criteria fordefiningmultipotent mesenchymal stromal cells. The InternationalSociety for Cellular Therapy position statement. Cytotherapy.2006;8(4):315-317.
5. Alvarez R, Lee HL, Hong C, Wang CY. Single CD271 marker isolates mesenchymal stem cellsfrom human dental pulp. Int J Oral Sci. 2015; 7(4): 205-212.

6. Rose RA, Jiang H, Wang X, Helke S, Tsoporis JN, Gong N, Keating SC, Parker TG,Backx PH, Keating A. Bone marrow-derived mesenchymal stromal cells express cardiac-specific markers, retain the stromal phenotype, and do not become functionalcardiomyocytes in vitro. Stem Cells. 2008; 26(11): 2884-2892.

7. Qian H, Yang H, Xu W, Yan Y, Chen Q, Zhu W, Cao H, Yin Q, Zhou H, Mao F, Chen Y. Bone marrow mesenchymal stem cells ameliorate rat acute renalfailure by differentiation into renal tubular epithelial-like cells. Int J Mol Med.2008; 22(3): 325332.

8. Cho KA, Ju SY, Cho SJ, Jung YJ, Woo SY, Seoh JY, Han HS, Ryu KH. Mesenchymalstem cells showed the highest potential for theregeneration of injured liver tissue compared with other subpopulations of the bonemarrow. Cell Biol Int. 2009; 33(7): $772-777$.

9. HanF, Wang CY, Yang L, Zhan SD, Zhang M, Tian K. Contribution of murine bone marrow mesenchymal stem cells topancreas regeneration after partial pancreatectomy in mice. Cell Biol Int. 2012; 36(9): 823-831.

10. Robey TE, Saiget MK, Reinecke H, Murry CE. Systemsapproaches to preventing transplanted cell death in cardiac repair.JMol Cell Cardiol. 2008; 45(4): 567-581.

11. Mastri M, Lin H, Lee T. Enhancing the efficacy of mesenchymalstem cell therapy. World J Stem Cells. 2014; 6(2): 82-93.

12. Ying Wang, Xiaodong Chen, Wei Cao, Yufang Shi. Plasticity of mesenchymal stem cells in immunomodulation: pathological and therapeutic implication. Nat Immunol. 2014; 15(11): 1009-1016.

13. Ren G, Zhang L, Zhao X, Xu G, Zhang Y, Roberts AI, Zhao RC, Shi Y. Mesenchymal stem cell-mediated immunosuppression occurs viaconcerted action of chemokines and nitric oxide. Cell Stem Cell. 2008; 2(2): 141-150.

14. Sudres M, Norol F, Trenado A, Grégoire S, Charlotte F, Levacher B, Lataillade JJ, Bourin P, Holy X, Vernant JP, Klatzmann D, Cohen JL. Bone marrow mesenchymal stem cells suppress lymphocyteproliferation in vitro but fail to prevent graft-versus-host disease in mice. JImmunol.2006; 176(12): 7761-7767.

15. Di Nicola M, Carlo-Stella C, Magni M, Milanesi M, Longoni PD, Matteucci P, Grisanti S, Gianni AM. Human bone marrow stromal cells suppress T-lymphocyteproliferation induced by cellular or nonspecific mitogenic stimuli. Blood. 2002; 99(10): 3838-3843.

16. Bartholomew A, Sturgeon C, Siatskas M, Ferrer K, McIntosh K, Patil S, Hardy W,Devine S, Ucker D, Deans R, Moseley A, Hoffman R. Mesenchymal stem cells suppress lymphocyte proliferationin vitro and prolong skin graft survival in vivo. Exp Hematol. 2002; 30(1): 42-48.

17. Le Blanc K, MougiakakosD. Multipotent mesenchymal stromal cells and theinnate immune system. Nat Rev Immunol. 2012; 12(5): 383-396.

18. Uccelli A, Moretta L, PistoiaV. Mesenchymal stem cells in health and disease.Nat Rev Immunol. 2008; 8(9): 726-736.

19. Shi Y, Su J, Roberts AI, Shou P, Rabson AB, Ren G. How mesenchymal stem cells interact with tissue immune responses.Trends Immunol. 2012; 33(3): 136-143.

20. BernardoME, FibbeWE. Mesenchymal stromal cells: sensors and switchers of inflammation. Cell Stem Cell. 2013; 13(4): 392-402.

21. Németh K, Leelahavanichkul A, Yuen PS, Mayer B, Parmelee A, Doi K, Robey PG,Leelahavanichkul K, Koller BH, Brown JM, Hu X, Jelinek I, Star RA, Mezey E. Bone marrow stromal cells attenuate sepsis via prostaglandinE(2)-dependent reprogramming of host macrophages to increase their interleukin-10production. Nat Med. 2009; 15(1): 42-49.

22. Abumaree MH, Al Jumah MA, Kalionis B, Jawdat D, Al Khaldi A, Abomaray FM,Fatani AS, Chamley LW, Knawy BA. Human placental mesenchymal stem cells (pMSCs) play a roleas immune suppressive cells by shifting macrophage differentiation from inflammatoryM1 to anti-inflammatory M2 macrophages. Stem Cell Rev. 2013; 9(5): 620-641.

23. Li W, Ren G, Huang Y, Su J, Han Y, Li J, Chen X, Cao K, Chen 
Q, Shou P, Zhang L, Yuan ZR, Roberts AI, Shi S, Le AD, Shi Y. Mesenchymal stem cells: a double-edged sword in regulating immuneresponses. Cell Death Differ. 2012; 19(9): 1505-1513.

24. Li MO, Flavell RA. Contextual regulation of inflammation: a duet by transforminggrowth factor- $\beta$ and interleukin-10. Immunity. 2008; 28(4): 468-476.

25. Ren G, Zhang L, Zhao X, Xu G, Zhang Y, Roberts AI, Zhao RC, Shi Y. Mesenchymal Stem Cell-MediatedImmunosuppression Occurs via ConcertedAction of Chemokines and Nitric Oxide. Cell Stem Cell. 2008; 2(2): 141-150.

26. Lazzeri E, Romagnani P. CXCR3-binding chemokines: Novelmultifunctional therapeutic targets. Curr. Drug Targets Immune Endocr. Metabol. Disord. 2005; 5(1): 109-118.

27. Chan JL, Tang KC, Patel AP, Bonilla LM, Pierobon N, Ponzio NM, Rameshwar P. Antigen-presenting property of mesenchymal stem cells occurs during anarrow window at low levels of interferon- $\gamma$. Blood. 2006; 107(12): 4817-4824.

28. Krampera M, Cosmi L, Angeli R, Pasini A, Liotta F, Andreini A Santarlasci V, Mazzinghi B, Pizzolo G, Vinante F, Romagnani P, Maggi E, Romagnani S, Annunziato F. Role forinterferon- $\gamma$ in the immunomodulatory activity of human bone marrowmesenchymal stem cells. Stem Cells. 2006; 24(2): 386398.

29. Meisel R, Zibert A, Laryea M, Göbel U, Däubener W, Dilloo D. Human bonemarrow stromal cells inhibit allogeneic T-cell responses by indoleamine 2, 3-dioxygenase-mediated tryptophan degradation. Blood. 2004; 103(12):4619-4621.

30. Ren G, Zhang L, Zhao X, Xu G, Zhang Y, Roberts AI, Zhao RC, Shi Y. Mesenchymal stemcell-mediated immunosuppression occurs via concerted action of chemokinesand nitric oxide. Cell Stem Cell. 2008;2(2):141-150.

31. Croitoru-Lamoury J, Lamoury FM, Caristo M, Suzuki K, Walker D, Takikawa O,Taylor R, Brew BJ. Interferon-gamma regulates the proliferation and differentiation of mesenchymal stem cells via activation of indoleamine 2,3 dioxygenase (IDO). PLoSOne. 2011;6(2):e14698.

32. Dorronsoro A, Ferrin I, Salcedo JM, Jakobsson E, Fernandez-Rueda J, Lang V,Sepulveda P, Fechter K, Pennington D, Trigueros C. Human mesenchymal stromal cells modulate T-cell responses throughTNF-a-mediated activation of NF-kB. Eur J Immunol. 2014;44(2):480-488.

33. Wang L, Zhao Y, Liu Y, Akiyama K, Chen C, Qu C, Jin Y, Shi S IFN-gamma and TNF-alpha synergistically induce mesenchymal stem cell impairment and tumorigenesisvia NFKB signaling. Stem Cells. 2013;31(7):1383-95.

34. Usui Y, Okunuki Y, Hattori T, Kezuka T, Keino H, Ebihara N, Sugita S, Usui M, Goto H, Takeuchi M. Functional expression ofB7H1 on retinal pigment epithelial cells.Exp Eye Res.2008;86(1):52-59.

35. Vigo T, Procaccini C, Ferrara G, Baranzini S, Oksenberg JR, Matarese G, Diaspro A,Kerlero de Rosbo N, Uccelli A. IFN- $\gamma$ orchestrates mesenchymal stem cellplasticity through the signal transducer andactivator of transcription 1 and 3 and mammaliantarget of rapamycin pathways. J Allergy Clin Immunol. 2017; 139(5): 1667-1676.

36. Qing Y, Stark GR. Alternative activation of STAT1 and STAT3 in response to interferon-gamma. $J$ Biol Chem. 2004;279(40):41679-41685.

37. Ramana CV, Gil MP, Schreiber RD, Stark GR. Stat1-dependent and -independentpathways in IFN-gamma-dependent signaling. Trends Immunol.2002;23(2):96-101.

38. Laplante M, Sabatini DM. mTOR signaling in growth control and disease. Cell. 2012;149(2):274-293.

39. Dazert E, Hall MN. mTOR signaling in disease. Curr Opin Cell Biol. 2011;23(6):744-755.

40. Sheng H, Wang Y, Jin Y, Zhang Q, Zhang Y, Wang L, Shen B, Yin S, Liu W, Cui L, Li N. A critical role of IFN-gamma in priming MSC-mediated suppression of $\mathrm{T}$ cell proliferation through upregulation of B7-H1. Cell Res. 2008;18(8):846-857.

41. Ren G, Zhang L, Zhao X, Xu G, Zhang Y, Roberts AI, Zhao RC, Shi Y. Mesenchymal stemcell-mediated immunosuppression occurs via concerted action of chemokinesand nitric oxide. Cell Stem Cell. 2008;2(2):141-150.

42. Chinnadurai R, Copland IB, Patel SR, Galipeau J. IDO-Independent Suppression of $\mathrm{T}$ Cell Effector Function byIFN- $\gamma$-Licensed Human Mesenchymal Stromal Cells. J Immunol. 2014; 192(4): 1491-1501.
43. Meisel R, Zibert A, Laryea M, Göbel U, Däubener W, Dilloo D Human bone marrow stromal cells inhibit allogeneic T-cel responses by indoleamine 2,3-dioxygenase-mediated tryptophan degradation. Blood. 2004; 103(12):4619-4621.

44. Hong J, Hueckelhoven A, Wang L, Schmitt A, Wuchter P, Tabarkiewicz J, Kleist C,Bieback K, Ho AD, Schmitt M. Indoleamine 2,3-dioxygenase mediates inhibition of virus-specificCD8(+) $\mathrm{T}$ cell proliferation by human mesenchymal stromal cells. Cytotherapy. 2016; 18(5): 621-629.

45. Li R, Li H, Sun Q, Liu L, Zhang C, Ren X. Indoleamine 2,3-dioxygenase regulates $\mathrm{T}$ cell activity throughVav1/Racpathway. Mol Immunol. 2017; 81: 102-107.

46. Gianchecchi E, Delfino DV, Fierabracci A.Recent insights into the role of thePD-1/PD-L1 pathway in immunological tolerance andautoimmunity.Autoimmun Rev.2013;12(11):1091-1100.

47. Parry RV, Chemnitz JM, Frauwirth KA,Lanfranco AR, Braunstein I, Kobayashi SV,Linsley PS, Thompson CB, Riley JL. CTLA-4 and PD-1 receptors inhibit T-cellactivation by distinct mechanisms. Mol CellBiol. 2005;25(21):9543-9553.

48. Francisco LM, Salinas VH, Brown KE, Vanguri VK, Freeman GJ, Kuchroo VK, Sharpe AH.PD-L1 regulates the development,maintenance, and function of inducedregulatory $\mathrm{T}$ cells. J Exp Med. 2009;206(13):3015-3029.

49. Bennett F, Luxenberg D, Ling V,Wang IM, Marquette K, Lowe D, Khan N, Veldman G, Jacobs KA, Valge-Archer VE, Collins M, Carreno BM.Program death-1 engagement upon TCRactivation has distinct effects oncostimulation and cytokine-drivenproliferation: attenuation of ICOS, IL-4, and IL-21, but not CD28, IL-7, and IL-15 responses. JImmunol. 2003;170(2):711-718.

50. Salama AD, Chitnis T, Imitola J,Ansari MJ, Akiba H, Tushima F, Azuma M, Yagita H,Sayegh MH, Khoury SJ.Critical role of the programmed death-1 (PD-1) pathway in regulation of experimentalautoimmune encephalomyelitis. J Exp Med.2003;198(1):71-78.

51. Nishimura H, Minato $\mathrm{N}$, Nakano $\mathrm{T}$, Honjo T.Immunological studies on PD-1 deficientmice: implication of PD-1 as a negativeregulator for $B$ cell responses. Int Immunol.1998;10(10):1563-1572.

52. Fujiwara H, Maeda Y, Kobayashi K, Nishimori H, Matsuoka K, Fujii N, Kondo E, Tanaka T, Chen L, Azuma M, Yagita H, Tanimoto M.Programmed death-1 pathway in hos tissuesameliorates Th17/Th1-mediatedexperimental chronic graft-versus-hostdisease. J Immunol. 2014;193(5):2565-2573.

53. Won TJ, Jung YJ, Kwon SJ, Lee YJ, Lee DI, Min H, Park ES, Joo SS, Hwang KW.Forcedexpression of programmed death-1 gene on Tcell decreased the incidence of type 1diabetes. Arch Pharm Res. 2010;33(11):1825-1833.

54. Chinnadurai R, Copland IB, Patel SR, Galipeau J.IDO-independent suppression of $\mathrm{T}$ celleffector function by IFN-gamma-licensedhuman mesenchymal stromal cells. JImmunol. 2014;192(4):1491-1501.

55. Ghiotto M, Gauthier L, Serriari N,Pastor S, Truneh A, Nunès JA, Olive D.PD-L1 and PD-L2 differ in their molecularmechanisms of interaction with PD-1. IntImmunol. 2010;22(8):651-660

56. Augello A, Tasso R, Negrini SM,Amateis A, Indiveri F, Cancedda R, Pennesi G.Bone marrow mesenchymal progenitor cellsinhibit lymphocyte proliferation by activationof the programmed death 1 pathway. Eur JImmunol. 2005;35(5):1482-1490.

57. Brunet A, Bonni A, Zigmond MJ,Lin MZ, Juo P, Hu LS, Anderson MJ, Arden KC,Blenis J, Greenberg ME. Aktpromotes cell survival by phosphorylating andinhibiting a Forkhead transcription factor.Cell. 1999;96(6):857-868.

58. Lin L, Hron JD, Peng SL. Regulation of NF-kappaB, Th activation, and autoinflammationby the forkhead transcription factor Foxo3a.Immunity.2004;21(2):203-213.

59. Carosella ED, HoWangYin KY, Favier B, LeMaoult J. HLA-G-dependent suppressor cells: Diverse by nature, function, andsignificance. Hum Immunol. 2008;69(11):700-707.

60. Götherström C, West A, Liden J, Uzunel M, Lahesmaa R, Le Blanc K. Difference in geneexpression between human fetal liver and adult bone marrowmesenchymal stem cells. Haematologica. 2005;90(8):1017-1026.

61. Chang CJ, Yen ML, Chen YC, Chien CC, Huang HI, Bai CH, Yen BL. Placenta-derivedmultipotent cells exhibit 
immunosuppressive properties thatare enhanced in the presence of interferon-gamma. StemCells. 2006;24(11):2466-2477.

62. Teklemariam T, Purandare B, Zhao L, Hantash BM. Inhibition ofDNA methylation enhances HLA-G expression in humanmesenchymal stem cells. Biochem Biophys Res Commun.2014;452(3):753-759.

63. Lo’ pez AS, Alegre E, LeMaoult J,Carosella E, González A. Regulatory role oftryptophan degradation pathway in HLA-G expression byhuman monocyte-derived dendritic cells. Mol Immunol.2006;43(14):2151-2160.

64. Alegre E, Rizzo R, Bortolotti D, Fernandez-Landázuri S, Fainardi E, González A. Some basic aspects ofHLA-G biology. J Immunol Res. 2014;2014:657625.

65. Kanai T, Fujii T, Kozuma S, Yamashita T, Miki A, Kikuchi A Taketani Y. Soluble HLA-G influencesthe release of cytokines from allogeneic peripheral bloodmononuclear cells in culture. Mol Hum Reprod.2001;7(2):195-200.

66. Ketroussi F, Giuliani M, Bahri R, Azzarone B, Charpentier B, Durrbach A. Lymphocyte cell-cycle inhibition by HLA-G is mediated by phosphatase SHP-2 and acts on the mTOR pathway. PLoS One. 2011;6(8):e22776.

67. Własiuk P, Putowski M, Giannopoulos K. PD1/PD1L pathway, HLA-G and $\mathrm{T}$ regulatory cells as newmarkers of immunosuppression in cancers. Postepy Hig Med Dosw. 2016; 70(0): 1044-1058.

68. Smith WL, Garavito RM, DeWitt DL. Prostaglandinendoperoxide $\mathrm{H}$ synthases (cyclooxygenases)-1 and -2. J BiolChem. 1996;271(52):33157-33160.

69. Kleiveland CR, Kassem M, Lea T. Human mesenchymalstem cell proliferation is regulated by PGE2 through differential activation of cAMP-dependent protein kinase isoforms.Exp Cell Res. 2008;314(8):1831-1838.

70. Aggarwal S, Pittenger MF. Human mesenchymal stem cellsmodulate allogeneic immune cell responses. Blood. 2005;105(4):1815-1822.

71. Najar M, Raicevic G, Boufker HI,Fayyad Kazan H, De Bruyn C, Meuleman N, Bron D, Toungouz M, Lagneaux L. Mesenchymalstromal cells use PGE2 to modulate activation and proliferation of lymphocyte subsets: Combined comparison ofadipose tissue, Wharton's Jelly and bone marrow sources.Cell Immunol.2010;264(2):171-179.

72. Prigione I, Benvenuto F, Bocca P, Battistini L, Uccelli A, Pistoia V. Reciprocalinteractions between human mesenchymal stem cells and $\gamma \delta \mathrm{T}$ cells orinvariant natural killer T cells. Stem Cells. 2009;27(3): 693-702.

73. Cheon H, Rho YH, Choi SJ, Lee YH, Song GG, Sohn J, Won NH, Ji JD. Prostaglandin E2augments IL-10 signaling and function. J Immunol. 2006;177(2):1092-1100.

74. Lu LY, Loi F, Nathan K, Lin TH, Pajarinen J, Gibon E, Nabeshima A, Cordova L, Jämsen E, Yao Z, Goodman SB. Pro-inflammatory M1 macrophages promote osteogenesis by mesenchymal stem cells viathe COX-2-Prostaglandin E2 Pathway. J Orthop Res. 2017; 35(11): 2378-2385.

75. Sheibanie AF, Yen JH, Khayrullina T, Emig F, Zhang M, Tuma $\mathrm{R}$, Ganea D. The proinflammatory effect of prostaglandin E2 in experimentalinflammatory bowel disease is mediated through the IL-23 $\rightarrow$ IL-17 axis. JImmunol. 2007;178(12):8138 - 8147.

76. Plumas J, Chaperot L, Richard MJ, Molens JP, Bensa JC, Favrot MC. Mesenchymal stemcells induce apoptosis of activated T cells. Leukemia. 2005;19(9):1597-1604

77. Skibinski G. The role of hepatocyte growth factor/c-metinteractions in the immune system. Arch Immunol Ther Exp(Warsz). 2003;51(5):277-282.

78. Di Nicola M, Carlo-Stella C, Magni M, Milanesi M, Longoni PD, Matteucci P, Grisanti S, Gianni AM. Human bonemarrow stromal cells suppress T-lymphocyte proliferationinduced by cellular or nonspecific mitogenic stimuli. Blood.2002;99(10):3838-3843.

79. Yen BL, Yen ML, Hsu PJ, Liu KJ, Wang CJ, Bai CH, Sytwu HK. Multipotent humanmesenchymal stromal cells mediate expansion of myeloid-derived suppressor cells via hepatocyte growth factor/c-metand STAT3. Stem Cell Reports.2013;1(2):139-151.

80. Rutella S, Bonanno G, Procoli A, Mariotti A, de Ritis DG, Curti A, Danese S, Pessina G, Pandolfi S, Natoni F, Di Febo A, Scambia G, Manfredini R, Salati S, Ferrari S,Pierelli L, Leone G, Lemoli RM. Hepatocyte growthfactor favors monocyte differentiation into regulatory interleukin (IL) $-10+$ + IL-12low/neg accessory cells with dendritic-cell features. Blood. 2006;108(1):218-227.

81. Chen PM, Liu KJ, Hsu PJ, Wei CF1, Bai CH, Ho LJ, Sytwu HK, Yen BL. Induction of immunomodulatory monocytes by human mesenchymal stem cell-derivedhepatocyte growth factor through ERK1/2. J Leukoc Biol.2014;96(2):295-303.

82. Mizuno S, Nakamura T. Improvement of sepsis by hepatocyte growth factor, an anti-inflammatory regulator: emerginginsights and therapeutic potential. Gastroenterol Res Pract.2012;2012:909350.

83. Kamimoto M, Mizuno S, Nakamura T. Reciprocal regulationof IL-6 and IL-10 balance by HGF via recruitment of hemeoxygenase-1 in macrophages for attenuation of liver injury ina mouse model of endotoxemia. Int $\mathrm{J}$ Mol Med. 2009;24(2):161-170.

84. Lee TH, Wisniewski HG, Vilcek J. A novel secretory tumornecrosis factor-inducible protein (TSG-6) is a member of thefamily of hyaluronate binding proteins, closely related to theadhesion receptor CD44. J Cell Biol.1992;116(2):545-557.

85. Lee RH, Oh JY, Choi H, Bazhanov N. Therapeutic factors secreted bymesenchymal stromal cells and tissue repair. J Cell Biochem.2011;112(11):3073-3078.

86. Kota DJ, Wiggins LL, Yoon N, Lee RH. TSG-6 produced byhMSCs delays the onset of autoimmune diabetes bysuppressing Th1 development and enhancing tolerogenicity.Diabetes. 2013;62(6):2048-2058.

87. Um S, Kim HY, Lee JH, Song IS, Seo BM. TSG-6 secreted by mesenchymal stem cells suppresses immunereactions influenced by BMP-2 through p38 and MEKmitogen-activated protein kinase pathway. Cell Tissue Res. 2017; 368(3): 551-561.

88. Liu L, Song H, Duan H, Chai J, Yang J, Li X, Yu Y, Zhang X, Hu X, Xiao M, Feng R, Yin H, Hu Q, Yang L, Du J, Li T. TSG-6 secreted by human umbilicalcord-MSCsattenuates severe burn-induced excessive inflammation viainhibiting activations ofP38 andJNK signaling. Sci Rep. 2016; 6: 30121.

89. Dyer DP, Salanga CL, Johns SC, Valdambrini E, Fuster MM, Milner CM, Day AJ, Handel TM. The Anti-inflammatory Protein TSG-6 Regulates ChemokineFunction by Inhibiting Chemokine/GlycosaminoglycanInteractions. J Biol Chem. 2016; 291(24): 12627-12640

90. Ng TH, Britton GJ, Hill EV, Verhagen J, Burton BR, Wraith DC Regulation of adaptiveimmunity; the role of interleukin-10. Front Immunol. 2013;4:129.

91. Joss A, Akdis M, Faith A, Blaser K, Akdis CA. IL-10 directly acts on $\mathrm{T}$ cellsby specifically altering the CD28 co-stimulation pathway. EurJ Immunol.2000;30(6):1683-1690.

92. Roncarolo M, Gregori S, Battaglia M, Bacchetta R, Fleischhauer K, Levings MK. Interleukin-10-secreting type 1 regulatory $\mathrm{T}$ cells in rodents and humans.Immunol Rev. 2006;212:28-50.

93. Ivanova-Todorova E, Bochev I, Dimitrov R, Belemezova K, Mourdjeva M, Kyurkchiev S, Kinov P, Altankova I, Kyurkchiev D. Conditioned medium from adipose tissue-derived mesenchymalstem cells induces CD4+FOXP3+ cells and increases IL-10secretion. J Biomed Biotechnol. 2012;2012:295167.

94. Quinn SR, O'Neill LA. The role of microRNAs in the controland mechanism of action of IL-10. Curr Top MicrobiolImmunol. 2014;380:145-155.

95. Hermankova B, Zajicova A, Javorkova E, Chudickova M, Trosan P, Hajkova M, Krulova M, Holan V. Suppression of IL-10 production by activated $B$ cells via a cellcontact-dependentcyclooxygenase-2 pathway upregulated inIFN- $\gamma$-treatedmesenchymal stem cells. Immunobiology. 2016; 221(2): 129-136.

96. Ma HC, Wang X, Wu MN, Zhao X, Yuan XW, Shi XL. Interleukin-10 Contributes to Therapeutic Effect ofMesenchymal Stem Cells for Acute Liver Failure via SignalTransducer and Activator of Transcription 3 SignalingPathway. Chin Med J. 2016; 129(8): 967-976.

97. Waterman RS, Tomchuck SL, Henkle SL, Betancourt AM. A new mesenchymal stem cell (MSC) paradigm: polarizationinto a pro-inflammatory MSC1 or an Immunosuppressive MSC2 phenotype. PLos One. 2010; 5(4): e10088.

98. van den Bosch MW, Palsson-Mcdermott E, Johnson DS,O'Neill 
LA. LPS induces the degradation of programmed cell deathprotein 4 (PDCD4) to release Twist2, activating c-Maftranscription to promote interleukin-10 production. J BiolChem. 2014;289(33):22980-22990.

99. Lo Furno D, Graziano AC, Caggia S, Perrotta RE, Tarico MS, Giuffrida R, Cardile V.Decrease ofapoptosis markers during adipogenic differentiation ofmesenchymal stem cells from human adipose tissue. Apoptosis.2013;18(5):578-588.

100. Lim JY, Im KI, Lee ES, Kim N, Nam YS,Jeon YW, Cho SG. Enhanced immunoregulation ofmesenchymal stem cells by IL-10-producing type 1 regulatory $\mathrm{T}$ cellsin collagen-induced arthritis. Sci Rep. 2016; 6: 26851

101. Sato K, Ozaki K, Oh I, Meguro A, Hatanaka K, Nagai T, Muroi $\mathrm{K}$, Ozawa K. Nitric oxide plays a critical role in suppression of T-cell proliferation by mesenchymal stem cells. Blood. 2007; 109(1): 228-234

102. Mattila JT, Thomas AC. Nitric oxide synthase: non-canonicalexpression patterns.Front Immunol. 2014;5:478.

103. Yan K, Zhang R, Chen L, Chen F, Liu Y, Peng L, Sun H, Huang W, Sun C, Lv B, Li F,Cai Y, Tang Y, Zou Y, Du M, Qin L, Zhang H, Jiang X. Nitric oxide-mediatedimmunosuppressive effect of human amniotic membrane-derived mesenchymal stem cells on the viability and migrationof microglia. Brain Res 2014;1590:1-9.

104. Lin CC, Shih $\mathrm{CH}$, Yang YL, Bien MY, Lin CH, Yu MC, Sureshbabu M, Chen BC.Thrombin induces inducible nitric oxide synthase expression via the MAPK, MSK1, and NF-kappaB signaling pathways in alveolar macrophages. Eur $\mathbf{J}$ Pharmacol. 2011; 672(1-3): 180-187,.

105. Nemeth K, Keane-Myers A, Brown JM, Metcalfe DD, Gorham JD, Bundoc VG, Hodges MG, Jelinek I, Madala S, Karpati S, Mezey E. Bone marrowstromal cells use TGF-beta to suppress allergic responses in amouse model of ragweed-induced asthma. Proc Natl Acad SciU S A. 2010;107(12):5652-5657.

106. Xu C, Yu P, Han X, Du L, Gan J, Wang Y, Shi Y. TGF- $\beta$ promotes Immune Responses in the Presence of Mesenchymal Stem Cells. J Immunol. 2014; 192(1): 103-109.

107. Aghajanova L. Leukemia inhibitory factor and humanembryo implantation. Ann N Y Acad Sci. 2004;1034:176-183.
108. Linker RA, Kruse N, Israel S, Wei T, Seubert S, Hombach A, Holtmann B, Luhder F,Ransohoff RM, Sendtner M, Gold R. Leukemia inhibitoryfactor deficiency modulates the immune response and limitsautoimmune demyelination: a new role for neurotrophiccytokines in neuroinflammation. J Immunol. 2008;180(4):2204-2213.

109. Banner LR, Patterson PH, Allchorne A, Poole S, Woolf CJ. Leukemiainhibitory factor is an anti-inflammatory and analgesiccytokine. J Neurosci. 1998;18(14):5456-5462.

110. Nasef A, Zhang YZ, Mazurier C, Bouchet S, Bensidhoum M, Francois S, Gorin NC,Lopez M, Thierry D, Fouillard L, Chapel A. Selected Stro-1-enriched bone marrow stromal cells display a majorsuppressive effect on lymphocyte proliferation. Int $\mathrm{J}$ LabHematol. 2009;31(1):9-19.

111. Wetzler M, Talpaz M, Lowe DG, Baiocchi G, Gutterman JU, Kurzrock R. Constitutiveexpression of leukemia inhibitory factor RNA by humanbone marrow stromal cells and modulation by IL-1, TNF-alpha, and TGF-beta. Exp Hematol. 1991;19(5):347-351.

112. Najar M, Raicevic G, Boufker HI, Fayyad-Kazan H, De Bruyn C, Meuleman N, Bron D, Toungouz M, Lagneaux L. Adipose-tissue-derived and Wharton's jelly-derived mesenchymal stromalcells suppress lymphocyte responses by secreting leukemiainhibitory factor. Tissue Eng Part A 2010;16(11):3537-3546.

113. Bamberger AM, Jenatschke S, Schulte HM, Löning T, Bamberger MC. Leukemiainhibitory factor (LIF) stimulates the human HLA-Gpromoter in JEG3 choriocarcinoma cells. J Clin EndocrinolMetab. 2000;85(10):3932-3936.

114. Dallagi A, Girouard J, Hamelin-Morrissette J, Dadzie R, Laurent L, Vaillancourt C,Lafond J, Carrier C, Reyes-Moreno C. Theactivating effect of IFN- $\gamma$ on monocytes/macrophages isregulated by the LIF-trophoblast-IL-10 axis via Statlinhibition and Stat3 activation. Cell Mol Immunol. 2015;12(2):326-341.

115. Striz I, Brabcova E, Kolesar L, Sekerkova A. Cytokine networking ofinnate immunitycells: a potential target of therapy. Clin Sci(Lond). 2014;126(9):593-612. 